\title{
RELATO DE EXPERIÊNCIA DE ESTÁGIO EM MATEMÁTICA NO ENSINO MÉDIO DA REDE ESTADUAL DE EDUCAÇÃO UTILIZANDO O SOFTWARE GEOGEBRA
}

\author{
REPORT OF EXPERIENCE OF INTERNSHIP IN MATHEMATICS IN THE HIGH SCHOOL \\ OF THE STATE EDUCATION NETWORK USING THE SOFTWARE GEOGEBRA
}

\author{
Mateus Vorpagel ${ }^{1}$ \\ Samuel Flores ${ }^{2}$ \\ Bárbara Eckert ${ }^{3}$ \\ Daiany Cristiny Ramos ${ }^{4}$
}

Alessandra Negrini Dalla Barba ${ }^{5}$

RESUMO: Este trabalho apresenta o relato de uma experiência da disciplina de estágio supervisionado, do curso de Licenciatura em Matemática, que foi realizado no segundo ano do Ensino Médio, em um colégio da rede estadual de educação. Para o desenvolvimento das atividades estudaram-se alguns trabalhos desenvolvidos por Wankel e Blessinger (2012), Dullius e Quartieri (2015) e Ibraihm (2016), para fundamentação teórica dessa pesquisa. Além disso, analisaram-se os Parâmetros Curriculares Nacionais para o Ensino Médio a fim de compreender melhor esse nível de ensino. Assistiu-se previamente seis aulas na turma na qual foi realizado o estágio, para fazer o levantamento dos conhecimentos prévios dos alunos. O conteúdo trabalhado foi Trigonometria no Triângulo Retângulo, onde se relacionou o conteúdo com o cotidiano dos estudantes, utilizando o software matemático Geogebra para os alunos simularem diferentes relações trigonométricas de modo a enriquecerem o aprendizado. No final do trabalho foi realizada uma avaliação individual escrita, onde mais de $60 \%$ da turma obteve nota acima da média.

Palavras-chave: Trigonometria. Experiência. Ensino. Ensino Médio.

ABSTRACT: This work presents the report of an experience of the supervised internship discipline, of the Mathematics Degree course, which was carried out in the second year of High School, in a state school. For the development of the activities, some studies developed by Wankel an (2012), Dullius and Quartieri (2015) and Ibraihm (2016) were studied, for the theoretical foundation of this research. In addition, the National Curriculum Parameters for Secondary Education was analyzed in order to better understand this level of education. Six classes were previously attended in the class in which the internship took place, to

\footnotetext{
${ }^{1}$ Graduado em Licenciatura em Matemática - Unopar, Graduado em Engenharia Elétrica - Univates, Mestrando em Ensino de Ciências Exatas - Univates. E-mail: vorpazoo8@gmail.com.

${ }^{2}$ Graduado em Licenciatura em Matemática - Universidade de Santa Cruz do Sul - Unisc, Mestrando em Ensino de Ciências Exatas - Univates. E-mail: samueldflores@universo.univates.br.

${ }_{3}^{3}$ Graduada em Letras - Unopar, Graduada em Direito - Unisinos. E-mail: barbaram.eckert@gmail.com.

4 Graduada em Licenciatura em Matemática - Universidade Federal de Lavras, Mestre em Matemática Universidade Federal de Lavras, Doutora em Ensino de Ciências e Educação Matemática - Universidade Estadual de Londrina. E-mail: daiany.ramos@educadores.net.br.

${ }_{5}^{5}$ Graduada em Bacharelado e Licenciatura em Matemática - Universidade Estadual de Londrina- UEL, Especialista em Educação Matemática - UEL, Mestre em Matemática Aplicada e Computacional - UEL. E-mail: alessandra.barba@educadores.net.br.
} 
survey the students' previous knowledge. The content worked on was Trigonometry in the Rectangle Triangle, where the content was related to the students' daily lives, using the Geogebra mathematical "software" so that students can simulate different trigonometric relations in order to enrich learning. At the end of the work, an individual written assessment was carried out, in which more than $60 \%$ of the class scored above average.

Keywords: Trigonometry. Experience.Teaching. High School.

\section{INTRODUÇÃO}

Este documento apresenta um relato e uma experiência de estágio que foi realizado no Colégio Estadual Presidente Castelo Branco, localizado no município de Lajeado, Rio Grande do Sul. Todas as atividades descritas neste relatório foram desenvolvidas no período de 20 de fevereiro a 30 de março de 2019, as quais foram supervisionadas pela professora Maria Isabel Eckhardt e orientadas pelas professoras Alessandra Negrini Dalla Barba e Daiany Cristiny Ramos.

Foram feitas as seguintes atividades: análise dos Parâmetros Curriculares Nacionais para o Ensino Médio a fim de compreender melhor esse nível de ensino, observação de seis aulas da turma escolhida para realização das atividades, regência (intervenção prática) onde se ministrou o conteúdo Trigonometria para uma turma de 20 alunos do $2^{\underline{a}}$ ano, fazendo uso de um software matemático chamado GeoGebra, pois as tecnologias permitem o envolvimento em diferentes atividades e contextos, tornando-se um meio alternativo e atrativo para a construção da aprendizagem (IBRAHIM et al., 20I6).

As aulas foram cuidadosamente preparadas para o estágio, de modo a que o uso das ferramentas tecnológicas não fosse vazio e sem significado, e este planejamento é importante assim como destaca Dullius e Quartieri (2015), onde classificam que a pontuação dos objetivos, as atividades a serem desenvolvidas e os questionamentos acerca da proposta, são fundamentais para o professor fazer uma boa prática com os recursos tecnológicos.

Esse relato vem ao encontro com a teoria de Vygostky e Piaget, pois conforme Coelho (2012), tais autores compartilham ideias de que a única aprendizagem significativa poderá ocorrer através da interação entre sujeito, objetos e outros sujeitos. Segundo Coelho (2012), as características humanas são resultadas de relações exteriores entre o homem e a sociedade, desse modo, o homem acaba transformando a si mesmo quando tenta transformar o meio, na busca de atender suas próprias necessidades.

Outro autor que se aplica neste trabalho é Paulo Freire. Segundo Gadoti (2012), Freire defendia uma educação popular, social e comunitária, que lutava pelo direito à educação, moradia, trabalho, saúde e segurança. Esse autor defendia a diversidade, em seu livro Pedagogia do oprimido, defende não apenas os oprimidos, mas também aqueles que lutam ao lado dos oprimidos. Freire acaba sendo fundamental no 
referencial teórico desse trabalho, em função das diferentes classes sociais que compõem a turma desse estágio.

Os recursos utilizados foram muito pertinentes para o aprendizado dos alunos, de maneira que fizesse com que os estudantes relacionassem o conteúdo com a vida social deles. Utilizou-se exemplos práticos de exercícios como calcular a distância percorrida por um avião na decolagem considerando diferentes ângulos de inclinação, a sombra que uma pessoa consegue produzir a partir dos raios solares incidindo sobre a mesma em diferentes ângulos e ainda a altura de uma montanha a partir da observação de um menino utilizando uma luneta. Ou seja, os alunos tiveram que pensar e usar o raciocínio lógico durante todo período das aulas, desta forma desenvolveram a capacidade de serem pessoas analíticas, além de aprender o conteúdo proposto.

Ao final das atividades propostas foi realizada uma avaliação em que a média atingida pela turma, ficou acima de 6o por cento. Destaca-se que todas as atividades tiveram o objetivo de aperfeiçoar os conhecimentos adquiridos durante as aulas, permitindo colocar em prática o conteúdo aprendido.

\section{MATERIAIS E MÉTODOS}

Este estudo foi realizado no Colégio Estadual Presidente Castelo Branco, localizado no município de Lajeado, Rio Grande do Sul, com os alunos do 2.ำ ano do Ensino Médio. A escolha pela turma se deu a partir da observação dos três anos que compõem o $2^{\circ}$ grau e optou-se por este ano pela afinidade com a classe. A professora, Supervisora de Campo, sugeriu que o conteúdo Trigonometria no Triângulo Retângulo fosse ministrado aos alunos, por fazer parte da sequência do conteúdo programado para ministrar no 2.․a ano do Ensino Médio.

Para elaboração do plano de aula e melhor escolha da metodologia trabalhada, assistiu-se seis períodos de aulas antes da intervenção prática. Para tanto utilizou-se da escuta sensível. De acordo com Barbosa (2008), escuta sensível é ouvir e interpretar aquilo que o outro quer aprender e de que forma, quer que aconteça, sem preconceitos ou prejuízos. Conforme Barbosa (2008, p. 215):

O educador e o educando fazem parte de um mesmo círculo produto de compreensão, expressão e intensidades cujo universo em seu conjunto é marcado por uma enorme quantidade de desejos entrecruzados e desconhecidos. A função do educador é elaborar junto ao educando um "sentido para o mundo", de forma que sejam respeitadas as diferenças culturais e todas as maneiras de sentir a realidade, sem imposição e assimilação de uma verdade excludente. O educador, no exercício da multirreferencialidade, abre-se ao mundo e a suas relações complexas e infinitas. 
Os conteúdos específicos como a história da trigonometria, relações do triângulo retângulo, teorema de Pitágoras, seno, cosseno e tangente, e problemas matemáticos nos triângulos retângulos, foram sugestões da professora titular.

Iniciou-se a primeira aula com a apresentação entre os professores e alunos, fazendo com que cada discente dissesse seu nome e sua idade, a fim de estabelecer um vínculo e deixar os alunos mais confortáveis.

Os conteúdos específicos que foram abordados nas aulas, se deram pelos seguintes:

- História da Trigonometria

- Relações do Triângulo Retângulo

- Teorema de Pitágoras

- Seno, Cosseno e Tangente

- Problemas matemáticos com Triângulos Retângulos

- Os objetivos dos estagiários com as propostas de ensino foram:

- Interpretar situações que envolvam o uso das relações trigonométricas.

- Aplicar corretamente o Teorema de Pitágoras.

- Calcular medidas desconhecidas utilizando as relações.

- Identificar e usar corretamente as relações: seno, cosseno e tangente.

- Resolver situações problemas envolvendo as relações trigonométricas.

As aulas foram expositivas para introduzir o conteúdo proposto com a resolução de exercícios, que foram corrigidos com os alunos de modo a sanar eventuais dúvidas.

A fim de dinamizar a aula e contribuir para uma aprendizagem significativa, foi utilizado um software matemático chamado GeoGebra de maneira que os alunos pudessem simular diferentes relações trigonométricas para enriquecer o aprendizado.

A Figura I apresenta algumas das simulações trigonométricas que foram realizadas durante as aulas. 
Figura I. Simulações trigonométricas realizadas durante as aulas.

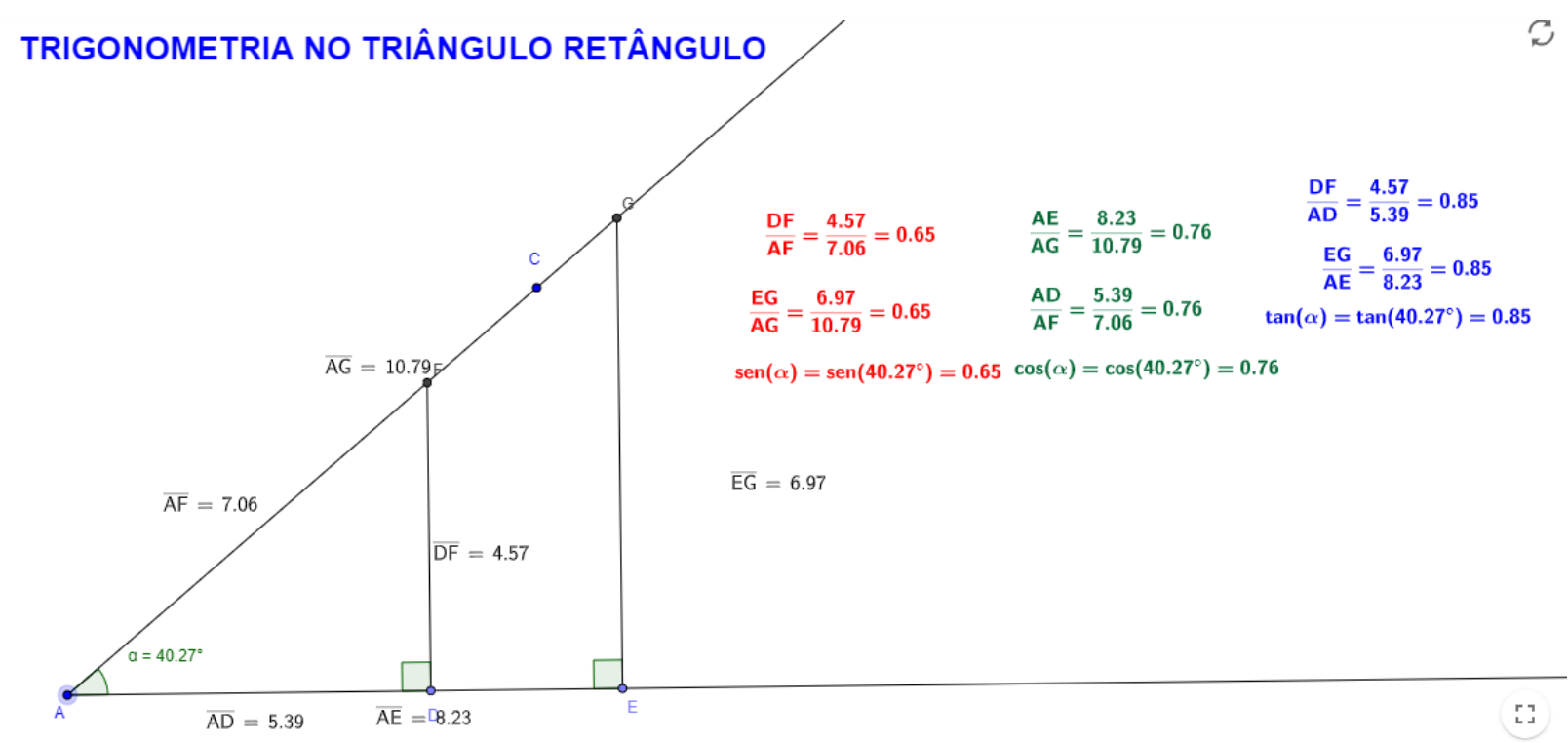

Fonte: Os Autores.

A partir das simulações no Geogebra os alunos puderam verificar o que ocorre com os ângulos internos do triângulo retângulo ao aumentar a hipotenusa e os catetos. Também verificaram as relações trigonométricas seno, cosseno e tangente.

Para finalizar o estágio, foi realizada uma atividade avaliativa, com o objetivo de analisar e avaliar a evolução dos educandos, visto que os alunos não tinham muito contato com ferramentas tecnológicas na sala de aula.

\section{RESULTADOS}

Os estudantes já possuíam conhecimento prévio sobre o tema, pois a turma já havia trabalhado os conteúdos de trigonometria no $8^{\circ}$ e 9. o ano do Ensino Fundamental, desse modo facilitou o entendimento dos alunos nas atividades. O conteúdo trabalhado pelo professor foi triângulo e, desta forma, todos já chegaram com uma boa base para entender a nova atividade.

Inicialmente, a turma apresentou pouco interesse pelo conteúdo. Entretanto, como as aulas foram bem dinâmicas, com a utilização de exemplos do cotidiano e software matemático, bem como os alunos foram conhecendo a metodologia trabalhada, eles foram se desinibindo e começaram a interagir e apresentar maior interesse pelas aulas.

Os recursos utilizados foram muito pertinentes para o aprendizado dos alunos, possibilitando-lhes relacionar o conteúdo com o cotidiano. 
No decorrer das aulas, os alunos foram desafiados a todo instante, dessa maneira tiveram que utilizar o raciocínio lógico e aliar a teoria à prática. $\mathrm{Na}$ avaliação individual sem consulta, a média foi acima de 6o por cento, ou seja, pôde-se perceber que os discentes conseguiram atingir a média para aprovação estipulada pela Instituição de Ensino. A avaliação individual foi composta por quatro questões de calcular as laterais e os ângulos de um triângulo retângulo e uma questão prática de calcular o comprimento de uma sombra a partir da altura do sujeito. Todas as questões tiveram o mesmo peso, sendo que cada uma correspondia a 20 por cento da nota da avaliação. A Tabela I apresenta o número de acertos dos alunos em cada questão.

Tabela I - Número de acertos de cada questão da avaliação individual

\begin{tabular}{|l|l|}
\hline Questã & $\begin{array}{l}\text { Número } \\
\text { Acertos }\end{array}$ \\
\hline I & I6 \\
\hline 2 & 15 \\
\hline 3 & 17 \\
\hline 4 & 16 \\
\hline 5 & 18 \\
\hline
\end{tabular}

Fonte: Os autores.

Analisando a Tabela I, percebe-se que o maior número de acertos foi na questão prática relacionada com o cotidiano dos alunos. Ao final das atividades também se questionou os estudantes a respeito daquilo que eles acharam de positivo durante o período de estágio e sugestões de melhorias que poderiam ser utilizadas em trabalhos futuros. A turma apontou como ponto positivo o fato de todas as atividades serem voltadas para o cotidiano dos alunos. Outro ponto marcante foi o de que nenhum dos alunos conhecia a ferramenta GeoGebra. A aprovação da ferramenta foi unânime. Para aulas futuras os alunos sugeriram ao professor trazer outras ferramentas tecnológicas para apresentar para a turma.

Para Piaget (1993), estas ferramentas podem se relacionar com a sua teoria construtivista, onde ela possibilita experiências envolvendo os estudantes, instigando-os e apoiando-os no processo de aprendizagem e fazendo com que o aluno construa seu próprio conhecimento a partir das descobertas individuais ou em grupo. E Dullius e Quartieri compartilham da mesma ideia, onde: 
O sucesso da aprendizagem dos alunos, nesse tipo de aula, depende da concretização de uma estratégia de ensino que pressupõe diversos momentos, mas em que o trabalho dos alunos com tarefas matemáticas, apoiado por recursos didáticos, ocupa uma posição central. Isso diverge claramente de uma outra perspectiva em que o professor expõe o conteúdo e o aluno, seguidamente exercita sobre questões estruturadas e dirigidas à assimilação de regras, procedimentos ou fatos (DULLIUS; QUARTIERI, 2015, p.14).

Mas vale ressaltar, também, que o simples fato de utilizar ferramentas tecnológicas em sala de aula, a fim de implementar o currículo, sem que se tenha um objetivo a ser alcançado, se torna dispensável, pois não desenvolverá, no estudante, uma aprendizagem significativa. Dullius e Quartieri (2016) dizem que a utilização da tecnologia digital, fomenta, no aluno, a aprendizagem, pois através da imagem pode potencializar a construção do conhecimento.

Apresentar, de diferentes formas, um mesmo elemento do conteúdo programático pode ajudar o aluno a compreender o tema que está sendo estudado. Além de revisitar, explorar o assunto via imagens ou animações, privilegiam o fazer pedagógico em sala de aula. A visualização é uma ação importante para a construção da aprendizagem, principalmente na área das Ciências Exatas (DULLIUS; QUARTIERI, 2or6, p.ro).

Diante disso, percebe-se que o uso das ferramentas tecnológicas vai muito além de simplesmente estarmos em um mundo tão digital ou por serem ferramentas atuais, pois se as atividades forem bem elaboradas, com objetivos claros a serem atingidos, tais recursos têm muita eficácia no auxílio da aprendizagem do estudante.

\section{DISCUSSÃO}

Como observado no capítulo anterior, inicialmente a atenção dos alunos era dispersa, pois muitos trabalham durante o dia para ajudar suas famílias e à noite vêm cansados e desmotivados às aulas. Paulo Freire que é um dos autores estudados nesse trabalho, lutava pelo direito à educação, moradia, trabalho, saúde e segurança das classes sociais mais baixas. (GADOTI, 2012).

Diante disso, com o andamento das atividades em que se buscou relacionar a teoria com o cotidiano dos alunos, acabou-se percebendo uma melhora na atenção da turma. Os alunos começaram a se interessar pelas atividades a partir do momento em que foi introduzido a ferramenta tecnológica Geogebra. Mesmo com dificuldades de mexer no software, em função de nenhum aluno da turma ter tido contato anteriormente, percebeu-se um interesse da turma muito grande pela ferramenta e rapidamente os alunos começaram a dominá-la.

Contudo, cabe ressaltar a diferença entre a simples aquisição de tecnologias e utilização delas para o ensino. Utilizar as tecnologias como ferramentas para o ensino e aprendizagem, exige muito mais do professor do que simplesmente adquiri-las, uma vez que esses recursos, segundo Amado (2015), podem 
ampliar significativamente o ensino, porém não podem substituir um ensino pobre. A introdução destes recursos no ensino e na aprendizagem é bastante complexa para os professores, pois são eles quem tem o poder de transformar a ferramenta em algo útil para a aprendizagem do discente, destaca a autora.

Em vista disso, para que o professor possa aproveitar ao máximo do recurso em sala de aula como um facilitador no processo de ensino e aprendizagem, sabe-se que não basta simplesmente querer inserir a tecnologia só para se adequar aos alunos nativos digitais, mas sim para que se tenha uma contribuição significativa. E, para isso, o professor precisa de um bom planejamento e que se tenha objetivos bastante claros a serem atingidos, para que o recurso se faça valer, além do que já se tem como ensino tradicional em sala de aula.

Fazendo uma análise dos dados obtidos a partir da avaliação individual da turma, percebeu-se que a questão que os alunos mais acertaram foi a da prática, onde tiveram que calcular a distância da sombra de uma pessoa a partir da sua altura e do ângulo que ela faz no solo. Isso mostra como questões práticas e do cotidiano conseguem motivar os alunos para uma aprendizagem significativa.

Todos os objetivos que foram previstos no plano de aula foram alcançados. O resultado foi satisfatório. A experiência foi muito importante para o crescimento tanto pessoal quanto intelectual de todos.

\section{CONSIDERAÇÕES FINAIS}

Este estudo proporcionou uma experiência desafiadora aos autores. Como hoje estamos em um mundo digital, as tecnologias têm de estar presentes no dia a dia das escolas, pois esta é a realidade do cotidiano.

De acordo com Wankel e Blessinger (2012), tecnologias digitais têm nos mostrado realmente o que é aprender no mundo atual, desenvolvendo a visão da aprendizagem coletiva a partir do uso de tecnologias digitais, de forma que o aprendizado seja agradável, instigante e interessante ao estudante. $\mathrm{O}$ uso de tecnologias digitais dinamiza as aulas e pode proporcionar maior participação e esforço dos estudantes, auxiliando professores a promover a aprendizagem através de atividades de ensino interativas, criativas e com significados para seus estudantes, para que possam desenvolver habilidades de tomada de decisão, afetivas e sociais.

Obviamente as tecnologias digitais não devem ser propostas pelo simples fato de inserirmos na educação, mas sim com objetivos bem específicos que possam auxiliar no processo de ensino e aprendizagem. As atividades propostas tiveram seus objetivos alcançados na proposta pedagógica exigida pela professora e isso foi gratificante. 
Os alunos além de conseguirem obter a média necessária para a aprovação, também conseguiram compreender os conteúdos trabalhados, mostrando interesse pelas atividades propostas durante a intervenção prática.

Desafios sempre estarão presentes em diariamente e momentos da vida acadêmica, porém cabe a cada um de nós optar pelas melhores escolhas e estratégias de ensino, sempre com o foco no estudante.

\section{Referências}

AMADO, N. Educ. Matem. Pesq., v. 17, n. 5, p. 1013-1039, 2015.

BARBOSA, Joaquim Gonçalves. Multirreferencialidade e produção do conhecimento: diferentes histórias de aprendizagens. Revista Educação em Questão, v. 32, n. I8, 2008.

COELHO, Luana; PISONI, Silene. Vygotsky: sua teoria e a influência na educação. Revista ePED, v. 2, n. I, p. 144-152, 2012.

DULliUS, M. M.; QUARTIERI, M. T. Explorando a matemática com aplicativos computacionais: anos iniciais do ensino fundamental. I ed. Editora Univates, Lajeado, 2015.

GADOTTI, Moacir. Educação popular, educação social, educação comunitária. In: Congresso

Internacional de Pedagogia Social. 2012.

IBRAHIM, Norshahila et al. Practitioners' validation on effectiveness of multimedia Mobile Learning Application for children. In: 2016 3rd International Conference on Computer and Information Sciences (ICCOINS). IEEE, 2016. p. I03-108.

PIAGET, J. A Evolução Intelectual da Adolescência à Vida Adulta. Trad. Fernando Becker; Tania B.I. Marques, Porto Alegre: Faculdade de Educação, 1993.

WANKEL, C.; BLESSINGER, P.; Increasing Student Engagement and Retention Using Immersive Interfaces: Virtual Worlds, Gaming, and Simulation. Emerald 20I2. Bingley-UK, 38I pp. 